\title{
2-D GEOELECTRICAL SURVEY FOR THE PRELIMINARY ROUTE OF THE NATURAL GAS PIPELINE INSTALLATION AT ALISTRATI CAVES, N. GREECE
}

\author{
Atzemoglou A. ${ }^{1}$ Tsourlos $\mathrm{P} .{ }^{2}$ and Vasiliadis C. ${ }^{1}$ \\ ${ }^{1}$ Institute of Geology and Mineral Exploration, 1 Fragon str, 54626, Thessaloniki, Greece (e-mail: \\ matzem@thes.igme.gr, Fax: +302310517071) \\ ${ }^{2}$ Department of Geophysics, School of Geology, Aristotle University of Thessaloniki, 54006 \\ Thessaloniki, Greece.
}

\section{ABSTRACT}

An extensive 2-D geoelectrical survey was carried out at the Alistrati caves, prefecture of Serres, N. Greece, as part of a preliminary route survey for the planned natural gas pipeline that was about to cross these regions of Northern Greece.

Geophysics can play a significant role in this procedure. Synthetic modeling and inversion examples presented in this work support the above claim.

The dipole-dipole array was used with inter-electrode spacing of $5 \mathrm{~m}$ and maximum dipole separation of $n$ equal to 8 dipole spacing. Two groups of personnel, including geophysicists and technicians, worked for one month to realize this survey. The number of measurements is really enormous for such type of research. A total of 7616 measurements (952 electrode points) were obtained. The area of investigation was chosen on the basis of the local geological conditions, which appeared to favor the existence of void structures. The survey line had a length of approximately $5 \mathrm{~km}$.

The 2-D geoelectrical survey proved to be an effective tool for delineating the subsurface lithology and structure of the surveyed area. Most importantly, the technique proved successful in locating highly karstified areas and can be used to aid void mapping as well as to provide useful information about their general setting.

\section{INTRODUCTION}

The cave of Alistrati is situated about $50 \mathrm{Km}$ SE of Serres and $25 \mathrm{Km} \mathrm{SW}$ from the city of Kavala. The cave has $3000 \mathrm{~m}$ length and covers about $25000 \mathrm{~m}^{2}$. The surveyed area was near the Alistrati caves (N. Greece), $6 \mathrm{Km}$ SE from the village of Alistrati. Not far from the cave, Agitis River is passed across. The route of the natural gas pipeline (branch of Kavala) was initially situated across the cave of Alistrati and there was a great possibility that during the cutting of the pipeline the cave of Alistrati would have great damage. So, there was at great priority to locate and avoid the shallow karstic voids (either air or clay filled) existed into the metamorphic formations of Rhodope massif.

A large-scale geoelectrical survey was conducted at the Alistrati caves (N. Greece) (Figure 1).

In particular, since karstified areas are effectively buried voids (either air or clay filled), they are ideal geophysical targets. 2-D electrical is a widely used technique for void detection. Many successful applications of the techniques can be found in literature (Dahlin 2001, Ward, 1989). These techniques were tested to the known voids and proved particularly successful.

One popular way to incorporate geology into the interpretation procedure is given from some concrete geological information (i.e. drill columns) to assume that certain properties of some geoelectrical layers are known. However, this approach effectively requires that prior geological knowledge is transformed successfully into concrete geoelectrical information and this is not always an easy task. 


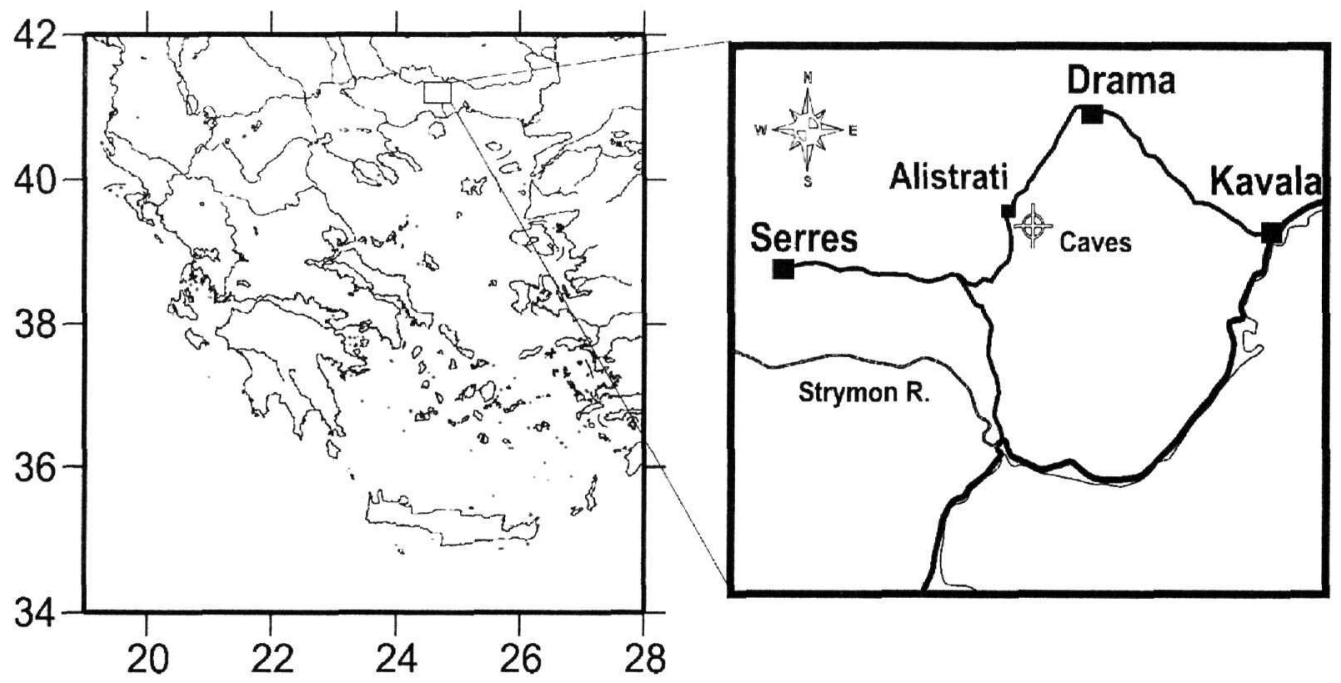

Figure 1: Location map of the study area

\section{GEOLOGICAL SETTING}

The studied area of Alistrati region (figure 2) belongs to the Rhodope massif, which is an old cratonic mass over lied by Paleozoic and Mesozoic metamorphic layers. The exact stratigraphy of the massif is very difficult to be interpreted due to intense tectonism and metamorphism. The layers of the Rhodope massif, which have a thickness of about $12 \mathrm{~km}$, can be divided in 3 major groups. An upper and lower group of gneisses and an intermediate group of marbles (case of Alistrati area). Alpine folding has strongly affected the Rhodope massif while simultaneous intrusions of granites of Mesozoic and Cenozoic age are widespread (between else: Ivanov, 1981; Kilias \& Moundrakis, 1990; Atzemoglou, 1997). In different basins, like the basins of Drama and Serres, the layers of Pliocene have been deposited on the metamorphic rocks. The well-known subsurficial karst of Alistrati and the possible smaller karsts that develop in the wider studied area are very possible to constitute a system of conjoined caves.

The studied area is covered by Tertiary formations, which consist of marls, conglomerates, sandstones and marly limestones. These formations cover the greater surficial area near the village of Alistrati. The low relief of the Alistrati area is due to these formations. In the wider area outcrop quaternary deposits and metamorphic formations of Paleozoic. In the studied area of the caves, the limestones are underlied the marls. More precisely, the formations of the wider area are the following:

1. Fluvial terraces consisting of sand, gravel, sandy gravel, sandy clays and rounded pebbles having thickness between 5 and $10 \mathrm{~m}$.

2. Terrestrial breccia-conglomerates consisting of coarse, unbedded, ungraded and cohesive breccia-conglomerate.

3. Reddish-brown loams with dispersed rounded pebbles: consisting of red clays, sandy loams with dispersed rounded pebbles mainly of marble.

4. Pliocene marls and marly limestones that are alternations of sandy marls, marls and marly limestones with white grey color.

5. Miocene conglomerates non-cohesive and marls mainly with gneiss and marble pebbles consolidated with marly cement.

6. Miocene compact conglomerates consisting of marble pebbles. Limestones bands are also found in the conglomerates. 
7. Paleozoic marbles and mica schist-gneisses. They belong to Rhodope massif. These formations constitute the geological background of the previous mentioned tertiary and quaternary deposits. The marbles are grey to whitish, coarse crystalline or micro crystalline, massive to bedded and locally platy marbles and the mica schist-gneisses are of low-grade metamorphism.

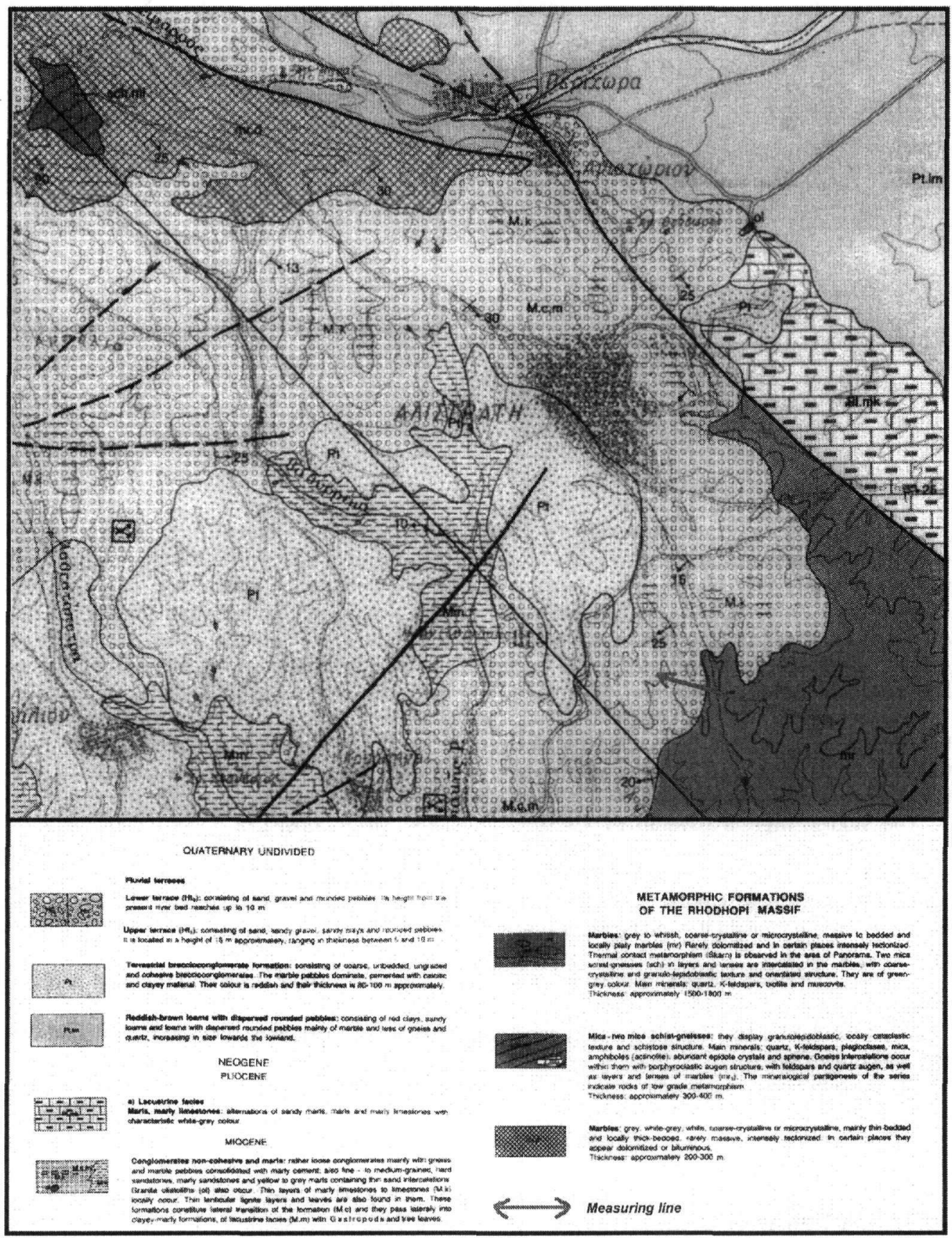

Figure 2: A synoptic geological map of the studied area (IGME, 1988). The measuring line is also drawn. 


\section{MODELLING AND PROCESSING}

2-D resistivity measured data in the form of pseudosections of apparent resistivity produce a distorted image of the subsurface resistivity. Inversion is currently the standard procedure to obtain a realistic estimate of the true resistivity based on the field observations. Among others, the smoothness constraint inversion (Constable et al, 1987) has become the most popular for interpreting ERT data since it produces a simplified subsurface resistivity model which is a reasonable representation of the subsurface and at the same time guarantees inversion stability.

In this work a flexible non-linear 2-D scheme (Tsourlos, 1995; Tsourlos et al., 1998) based on a smoothness constrained algorithm was used to invert the collected resistivity data. The aim of the inversion is to construct an estimate of a subsurface resistivity distribution, which is consistent with the experimental data. The algorithm is iterative and fully automated and is based on a reliable 2.5D finite element forward modeling scheme, which is also used for calculating the Jacobian matrix when necessary. The smoothness inversion scheme, used in this work, tries to calculate a subsurface resistivity estimate $\mathbf{x}$ for which the difference $\mathbf{d y}$ between the observed data $\mathbf{d}_{\mathrm{obs}}$ and the modeled data $d_{\text {calc }}$ (calculated using the forward modeling technique) is minimized under the condition that the roughness of the produced model is minimized. The resistivity correction at the $k+1$ iteration is given by:

$$
d \mathbf{x}_{k+1}=\left[\left(\mathbf{J}_{k}^{\top} \mathbf{J}_{k}+\mu \mathbf{C}_{x}^{\top} \mathbf{C}_{x}+\mathbf{C}_{z}^{\top} \mathbf{C}_{z}\right)\right]^{-1} \mathbf{J}_{k}^{\top} \mathbf{J}_{k} d \mathbf{y}_{k}
$$

where $\mathbf{C}_{\mathrm{x}}, \mathbf{C}_{\mathrm{z}}$ are matrices which describe the smoothness pattern of the model in the $x, z$, directions, $\boldsymbol{J}_{\mathrm{k}}$ is the Jacobian matrix estimate and $\boldsymbol{\mu}$ is the lagrangian multiplier.

a) Model

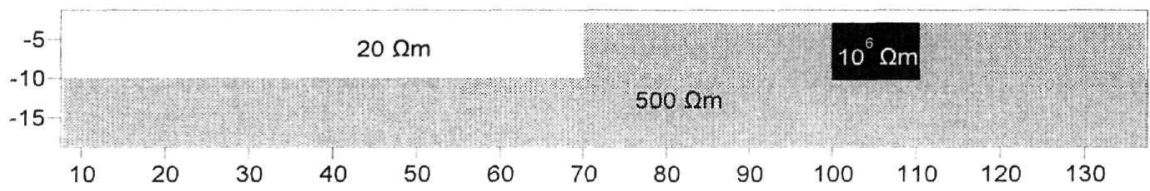

b) Pseudosection

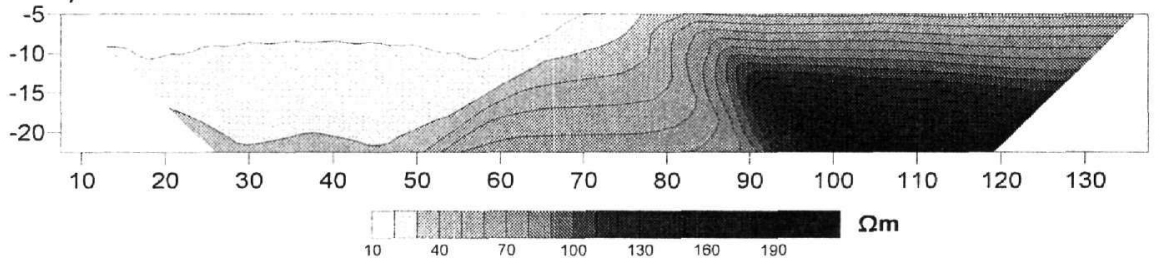

c) Inverted Section

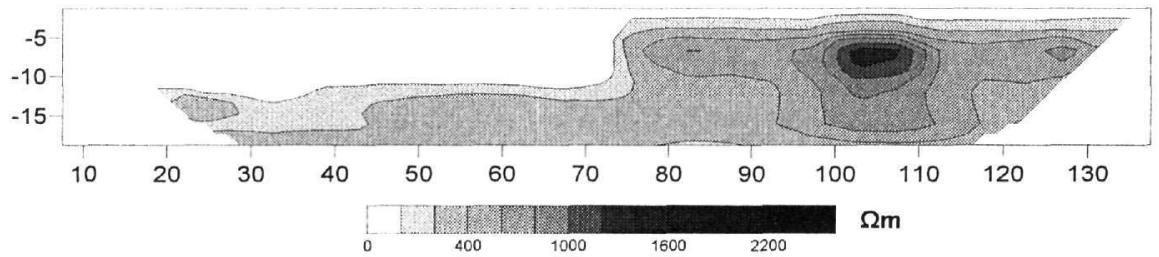

Figure 3: (a) Resistivity model (b) Synthetic data in a pseudosection form obtained for the model (a). (c) Inverted image of the synthetic resistivity data.

A proven 2.5D Finite Element Method (FEM) scheme was used as the platform for the forward resistivity calculations. In $2.5 \mathrm{D}$ modelling the change in resistivity is considered to be twodimensional but the current flow pattern is a three dimensional one. In other words, the measured values correspond to a three dimensional subsurface where the resistivity is allowed to vary in only 
two dimensions and remains constant in the strike direction. The adjoin equation approach was incorporated into the FEM scheme in order to calculate the Jacobian matrix $\mathbf{J}$.

To illustrate the effectiveness of the above procedure the model of Figure $3 a$, which simulates a void within a resistive bedrock formation (i.e. limestone), was used. A sediment overburden of varying thickness is also included into the model. We produced a 2-D dipole-dipole data set using the 2.5 FEM forward modeling scheme. The obtained apparent resistivity data, depicted in a pseudosection form in Figure $3 \mathrm{~b}$, were subsequently inverted and the results are shown in Figure 3c. The inverted subsurface resistivity image is very close to the initial model and is definitely a major improvement when compared to the pseudosection of Figure $3 \mathrm{~b}$, illustrating that voids are a particularly good target for the resistivity method even when they are placed within a resistive formation. Further the sediment layer is mapped accurately. Note that a similar processing procedure was followed for all the real data collected from the studied area.

\section{MEASUREMENTS AND INTERPRETATION}

All resistivity 2-D data sets were collected using the dipole-dipole array with a maximum $\mathrm{N}$ separation $\max _{N}=8$. During our measurements, we used an inter-electrode spacing of $5 \mathrm{~m}$ between the electrodes. Data were obtained with a SAS 300 Terrameter. The survey line was positioned between the $64.5 \mathrm{Km}$ and the $69.5 \mathrm{Km}$ of the initial planned pipeline (Vasiliadis, 1997).

a. INVERTED RESISTIVITY IMAGE (300-520m)
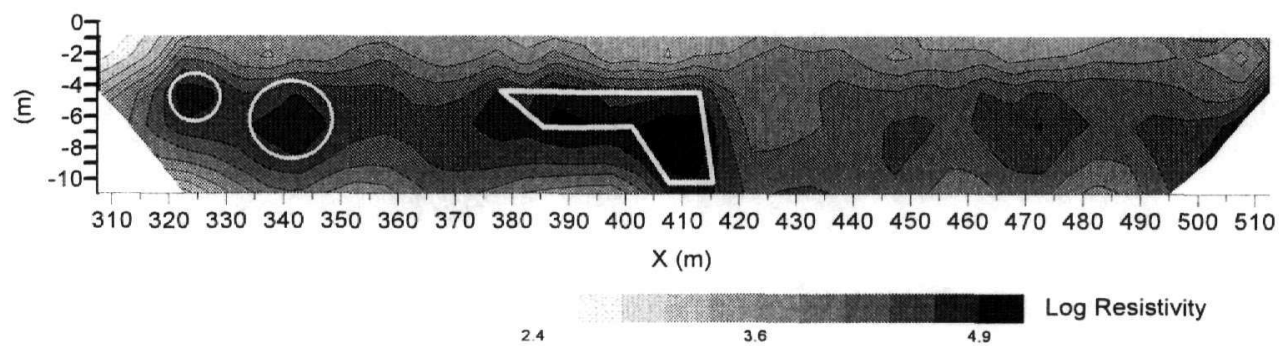

\section{b. INTERPRETATION}
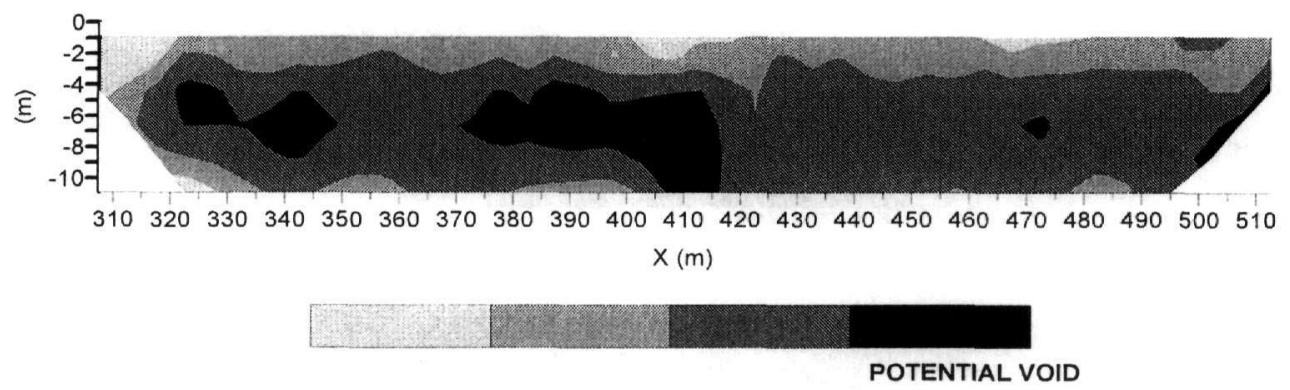

Figure 4: a) typical 2-D inversion section obtained from the area. Highly resistive features are noted as potential voids and b) interpretation of the inverted image.

Table 1: Resistivity ranges and their correlation to various geological features of the area.

\begin{tabular}{lll}
\hline & \multicolumn{1}{c}{ Resistivity (Ohm·m) } & \multicolumn{1}{c}{ Formation } \\
\hline 1. & $31<\rho_{\alpha}<3100\left(10^{1.5}<\rho_{\alpha}<10^{3.5}\right)$ & Non-cohesive conglomerates \\
2. & $3100<\rho_{\alpha}<10000\left(10^{3.5}<\rho_{\alpha}<10^{4}\right)$ & Compact conglomerates \\
3. & $10000<\rho_{\alpha}<40000\left(10^{4}<\rho_{\alpha}<10^{4.6}\right)$ & Marbles \\
4. & $\rho_{\alpha}>40000\left(\rho_{\alpha}>10^{4.6}\right)$ & Voids \\
\hline
\end{tabular}



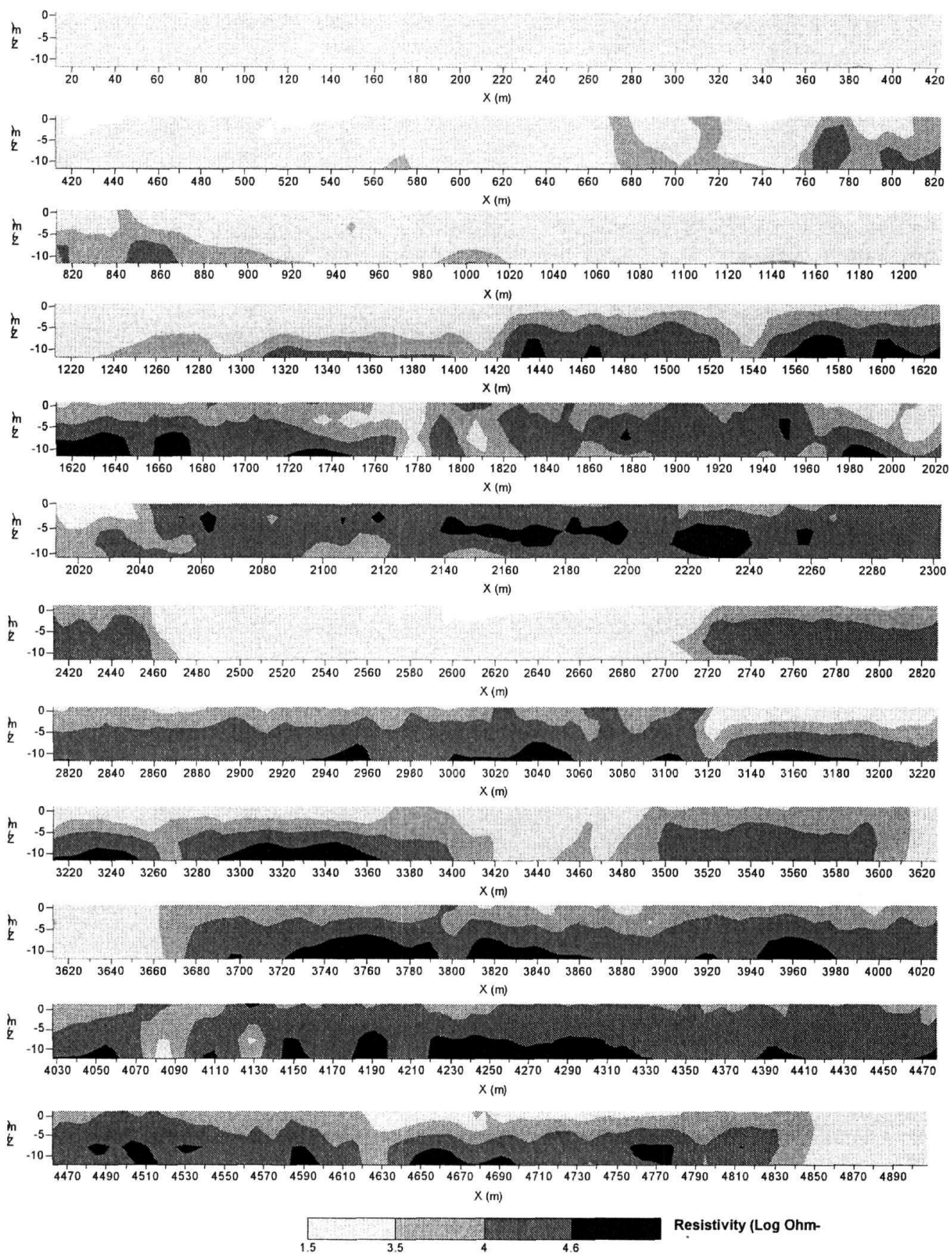

Figure 5: The interpreted geoelectrical image of the entire survey area.

The survey line has a length of $4760 \mathrm{~m}$. Because of this large length, we decided to divide this in 2 major sub lines having lengths of 2280m (KM64500) and 2480m (KM72000) respectively, which were inverted separately. Initially data were split into several sub-sections, which were inverted individually in order to facilitate processing and to further remove bad-quality data points. A typical inversion result is depicted in Figure 4 where highly resistive areas are clearly outlined (Fig 4a). Note 
also that the bedrock is clearly distinguished. In Figure $4 \mathrm{~b}$ results are presented with a different color scale in order to emphasize areas that are interpreted as potential voids or fracture zones.

Final results are produced by inverting the 2 major sub lines, despite their size, in order to avoid artificial discontinuities between the individual subsurface resistivity images. Subsequently each sub line was sub divided in segments of $400 \mathrm{~m}$ approximately solely for presentation purposes.

The overall picture presents high resistivities $\left(>10^{3} \mathrm{Ohm} * \mathrm{~m}\right)$, which are indicative of the marble. Yet, there are areas in which the resistivity is extremely high which is indicative of the existence of voids. Calibration tests over known test areas suggested that a resistivity value over $4 \cdot 10^{4} \mathrm{Ohm} \mathrm{m}^{*}$ is a reasonable threshold above which the existence of a void is highly possible. According to the above threshold the section is re-plotted in Figure 5 depicting the areas of non-cohesive conglomerates, the areas where there are compact conglomerates, the marbles regimes and the areas that are characterized as potential voids.

The interpreted results (based on Table1) for the entire area were taken into account in Figure 5. Several high resistive zones are recognized and interpreted as faults or fracture zones. This image is in good agreement with the geology of the studied area and suggests that the designed route of the pipeline in the area, onto the Alistrati cave, is not suitable for gas-pipe installation.

\section{CONCLUSIONS}

In the studied area, according to the in situ geological observations, the existence of big karstic structures, even below the superficial cover, was more than possible (Vasiliadis, 1997). The 2-D geoelectrical survey proved to be an effective tool for delineating the subsurface lithology and structure of the surveyed area. Besides the limitations of the used methodology (the dimensions of the caves cannot precisely defined), the technique proved totally successful in locating precisely the existing karstified places of the studied area.

The produced subsurface resistivity images can be easily understood by non-geophysicists and were particularly useful for redesigning the route of the natural gas pipeline. Based on the results of this research, the route of the natural gas pipeline was finally redesigned far from the cave of Alistrati and the neighbouring caves.

Conclusively, it is shown that geophysical surveys, especially with the modern equipment, can play a significant role in infrastructure planning by providing reliable results in a limited time and low costs.

\section{REFERENCES}

Atzemoglou, A. (1997). Paleomagnetic results from N. Greece and their contribution in the interpretation of the Tertiary geodynamic evolution of the area. D.Phil. Thesis, Aristotle University of Thessaloniki, Greece (in Greek).

Atzemoglou, A. (1998). Geophysical survey at Alistrati (Serres county). IGME, Internal report (in Greek).

Constable, S. Parker, R., and Constable C. (1987). Occam's inversion: A practical algorithm for generating smooth models from electromagnetic sounding data. Geophysics, 52, 289-300.

Dahlin, T. (2001). The development of DC resistivity imaging techniques. COMPUTERS \& GEOSCIENCES , 27 (9), 1019-1029

Geological map of Greece, Prosotsani sheet, IGME (1988).

Ivanov, R. (1981). The deep-seated central_Rhodope nappe and the interference tectonics of the Rhodope crystalline basement. Geol. Balkan., 11, 47-66.

Kilias, A. and Moundrakis, D. (1990). Kinematics of the crystalline sequences in the Western Rhodope massif. Geol. Rhodopica, 2, 100-116.

Tsourlos, P (1995). Modelling, interpretation and inversion of multi-electrode resistivity survey data. D.Phil. Thesis, University of York, U.K.

Tsourlos, P., Szymanski, J. and Tsokas, G. (1998). A smoothness constrained algorithm for the fast 2-D inversion of DC resistivity and induced polarization data. Journal of the Balkan Geophysical Society, 1, 1, 3-13.

Ward, S. (1989). Resistivity and induced polarization methods: in Investigations in Geophysics no 5, Geotechnical and Environmental Geophysics vol I, ed. S. Ward, SEG, Tulsa, 147-189.

Vasiliadis, C. (1997). Geophysical survey at the region of Alistrati (Serres County) across the preliminary route of natural gas pipeline, section of Kavala. IGME, Internal report (in Greek). 